\title{
The effect of a two-stage publication process on the Journal Impact Factor: a case study on the interactive open access journal Atmospheric Chemistry and Physics
}

\author{
Lutz Bornmann • Christoph Neuhaus $\cdot$ Hans-Dieter Daniel
}

Received: 9 February 2010/Published online: 4 June 2010

(C) Akadémiai Kiadó, Budapest, Hungary 2010

\begin{abstract}
Taking the interactive open access journal Atmospheric Chemistry and Physics as an example, this study examines whether Thomson Reuters, for the Journal Citation Reports, correctly calculates the Journal Impact Factor (JIF) of a journal that publishes several versions of a manuscript within a two-stage publication process. The results of this study show that the JIF of the journal is not overestimated through the two-stage publication process.
\end{abstract}

Keywords Journal Impact Factor · Open access · Peer review

The Journal Citation Reports (JCR) were introduced by Garfield (1976), founder of the Institute for Scientific Information (now Thomson Reuters, Philadelphia, PA, USA), as an instrument to evaluate the significance of scholarly journals. At first, the JCR's "origin and development was guided by the needs of US university and college librarians who wanted to use an objective method to select journals for their holdings" (Archambault and Larivière 2009, p. 636). Today, the most important journals (currently more than 8,200 journals from more than 3,300 publishers in 60 countries) are listed in the JCR with a series of bibliometric data and indicators (e.g., total citations, Journal Impact Factor (JIF), Journal Immediacy Index, Journal Cited Half-Life). Through the publication of the indicators, essentially the JIF, JCR has become an authority for evaluating scholarly journals (Amin and Mabe 2003; Magri and Solari 1996). Today, the JIF is one of the most important indicators in evaluative bibliometrics (Bornmann et al. 2007). It is used in the scientific community as a basis for decision making on research grants, hiring, and salaries (see here Kumar et al. 2009; Retzer and Jurasinski 2009).

L. Bornmann $(\bowtie) \cdot$ C. Neuhaus · H.-D. Daniel ETH Zurich, Zähringerstr. 24, 8092 Zurich, Switzerland e-mail: bornmann@gess.ethz.ch

H.-D. Daniel

University of Zurich, Evaluation Office, Zurich, Switzerland 
In recent years a number of problems have been pointed out that limit the validity of the JIF and the comparability of the values of different journals (see an overview in Glänzel and Moed 2002). Thus, according to Pendlebury (2009), the JIF can be "inflated in the numerator, in fact it is inflated, by 'free citations,' which are citations to article types, such as editorials or letters, not accounted for in the denominator" (p. 3, see here also Todd 2009). Further, the consideration given to journal self-citations in determining the JIF came to be a problem when "journal editors started to encourage authors to consider citing papers published in the journal where they had submitted their article for publication" (Archambault and Larivière 2009, p. 636). As an example of a journal for which the calculation of the JIF by Thomson Reuters can lead to problems, some publications looked at Angewandte Chemie International Edition (AC-IE). This journal is published in both an international edition (in English) and a German edition (Angewandte Chemie). The publications (see here Braun and Glänzel 1995; Moed et al. 1996) examined the question as to "whether the high JIF of Angewandte Chemie truly reflects the real impact of the journal, or as a result of double citations of both editions contains an overestimation" (Marx 2001, p. 140). Marx (2001) found that the JIF for AC-IE published in the JCR for the year 1998 is too high by about $15 \%$.

In this study we take the case of the interactive open access journal Atmospheric Chemistry and Physics (ACP) to examine a new problem that can limit the validity of the JIF for a journal: the publication of several versions of one and the same manuscript when a journal uses a two-stage publication process. The process of peer review and publication in the interactive scientific journal ACP differs from traditional scientific journals (Koop and Pöschl 2006; Pöschl 2004). ACP was launched in September 2001. It is published by the European Geosciences Union (EGU; http://www.egu.eu) and Copernicus Publications (http://publications.copernicus.org/) and is freely accessible via the Internet (www. atmos-chem-phys.org). ACP has the second highest annual JIF in the subject category 'Meteorology \& Atmospheric Sciences' (at 4.927 in the 2008 JCR, Science Edition).

In the first review stage at ACP, manuscripts that pass a rapid pre-screening process (access review) are immediately published as 'discussion papers' on the ACP Web site in Atmospheric Chemistry and Physics Discussions (ACPD). These discussion papers are then made available for interactive public discussion, the second review stage of ACP, during which the comments of designated reviewers (usually, the reviewers that already conducted the access review), additional comments by other interested members of the scientific community, and the authors' replies are published alongside the discussion paper. During the discussion phase, the designated reviewers are asked to review the discussion paper in detail. After the end of the discussion phase, every author has the opportunity to submit a revised manuscript taking into account the reviewers' comments and the comments of interested members of the scientific community. Based on the revised manuscript and in view of the access peer review and interactive public discussion, the editor accepts or rejects the revised manuscript for publication in ACP.

This means that papers that are published in ACP were previously published in ACPD in a more or less different version, and manuscripts that after the discussion phase are not published in ACP appeared beforehand in ACPD. Similar to double counting of citations to $\mathrm{AC}$-IE due to its international and German editions, the publication of several versions of a manuscript during and after the ACP peer review process could lead to a higher JIF, in that only the ACP papers enter into the denominator, whereas citations to both, the papers in $\mathrm{ACP}$ and the papers in ACPD, enter into the numerator. In this study, we examine whether the JIF is inflated in the case of journals that provide open access to submissions to peer review. ACP is particularly interesting here, because it has one of the highest JIFs in its 
subject category: The high JIF could be not only the result of the high quality of manuscripts and interactive open access (see here Kurtz and Brody 2006) but also an effect of the double counting of citations to discussion papers in ACPD and papers in ACP.

Table 1 shows the publication and citation counts that are listed in the JCR for the calculation of JIFs of ACP from 2006 to 2008. For example, a JIF of 4.927 for the year 2008 results from the 3,454 citations in 2008 to the 701 publications in 2006 und 2007. As the values in Table 1 show, the ACP increased its JIF from year to year. To investigate what influence the ACPD papers have on the JIFs of ACP reported in the JCR in recent years, we searched the citations to ACP and ACPD in the Science Citation Index Expanded (SCISEARCH) hosted by STN International by 'journal title matching' (see Marx 2001), i.e. we searched different variants of the journal title in the cited reference field of SCISEARCH. Table 2 shows the results of citation searching. The searching was performed for three variants of the journal title: The variant ATMOS CHEM PHYS is ACP, ATMOS CHEM PHYS DISC is ACPD, and ATMOSPHERIC CHEM PHYS refers mainly to papers in ACPD but also to papers in ACP. (In addition to these three, we found in SCISEARCH other variants of the journal title, but they received hardly any citations.) The column labeled 'JIF' in Table 2 shows the values that result from calculation using the citations for the different variants of the journal title. For instance, if the JIF for 2008 is calculated based only on citations for the journal title variant ATMOS CHEM PHYS (total = 3,298), the journal has a JIF of 4.705. If the JIF is calculated using citations for ATMOS CHEM PHYS and citations for ATMOSPHERIC CHEM PHYS, the JIF for 2008 is 4.863. This JIF differs only marginally from the JIF reported in the JCR for 2008 (4.927). The JIF calculated using the citations for all three journal title variants (5.508) differs clearly from the JIF published in the JCR. As Table 2 shows, these results are found not only for the JIF for 2008 but also for the JIFs for the two preceding years.

All in all, the results indicate that Thomson Reuters takes into account only those journal title variants into the calculation of the JIF that clearly do not include discussion papers. Only the variant ATMOSPHERIC CHEM PHYS (and not ATMOS CHEM PHYS

Table 1 JIFs of ACP published in the JCR

\begin{tabular}{|c|c|c|c|c|}
\hline \multicolumn{2}{|c|}{ Cites in 2008 to items published in } & \multicolumn{2}{|c|}{ Number of items published in } & \multirow{2}{*}{$\frac{\mathrm{JIF}}{4.927}$} \\
\hline 2006 & 1,946 & 2006 & 326 & \\
\hline 2007 & 1,508 & 2007 & 375 & \\
\hline Total & 3,454 & Total & 701 & \\
\hline \multicolumn{2}{|c|}{ Cites in 2007 to items published in } & \multicolumn{2}{|c|}{ Number of items published in } & JIF \\
\hline 2005 & 1,341 & 2005 & 239 & 4.865 \\
\hline 2006 & 1,408 & 2006 & 326 & \\
\hline Total & 2,749 & Total & 565 & \\
\hline \multicolumn{2}{|c|}{ Cites in 2006 to items published in } & \multicolumn{2}{|c|}{ Number of items published in } & JIF \\
\hline 2004 & 740 & 2004 & 170 & 4.362 \\
\hline 2005 & 1,044 & 2005 & 239 & \\
\hline Total & 1,784 & Total & 409 & \\
\hline
\end{tabular}

The JIF published by Thomson Reuters in the JCR is a quotient of the number of citable items published in a journal in a two-year period and their citations in the year thereafter 
Table 2 Calculation of JIFs using SCISEARCH

\begin{tabular}{|c|c|c|c|c|c|}
\hline YEAR & Journal title variant & Cites in 2007 & Cites in 2006 & Total & $\mathrm{JIF}^{\mathrm{a}}$ \\
\hline \multirow[t]{4}{*}{2008} & ATMOS CHEM PHYS & 1,442 & 1,856 & 3,298 & 4.705 \\
\hline & ATMOS CHEM PHYS DISC & 328 & 124 & 452 & \\
\hline & ATMOSPHERIC CHEM PHY & 30 & 81 & 111 & $4.863^{\mathrm{b}}$ \\
\hline & Total & 1,800 & 2,061 & 3,861 & 5.508 \\
\hline YEAR & Journal title variant & Cites in 2006 & Cites in 2005 & Total & $\mathrm{JIF}^{\mathrm{a}}$ \\
\hline \multirow[t]{4}{*}{2007} & ATMOS CHEM PHYS & 1,365 & 1,262 & 2,627 & 4.650 \\
\hline & ATMOS CHEM PHYS DISC & 199 & 174 & 373 & \\
\hline & ATMOSPHERIC CHEM PHY & 49 & 26 & 75 & $4.782^{b}$ \\
\hline & Total & 1,613 & 1,462 & 3,075 & 5.442 \\
\hline YEAR & Journal title variant & Cites in 2005 & Cites in 2004 & Total & $\mathrm{JIF}^{\mathrm{a}}$ \\
\hline \multirow[t]{4}{*}{2006} & ATMOS CHEM PHYS & 1,017 & 687 & 1,704 & 4.166 \\
\hline & ATMOS CHEM PHYS DISC & 266 & 89 & 355 & \\
\hline & ATMOSPHERIC CHEM PHY & 14 & 9 & 23 & $4.222^{\mathrm{b}}$ \\
\hline & Total & 1,297 & 785 & 2,082 & 5.090 \\
\hline
\end{tabular}

${ }^{\text {a }}$ For calculation of the JIF, the total number of items in Table 1 is used

b Taking into account the citations to ATMOS CHEM PHYS and ATMOSPHERIC CHEM PHY

DISC) evidently goes into the calculation, which refers mainly to papers in ACPD but also to papers in ACP. Thomson Reuters confirms (McVeigh 2010) that citations to any recognizable form of discussions are excluded from the calculation of the JIF.

In contrast to the case with AC-IE, our results indicate that when calculating the JIF of ACP, Thomson Reuters distinguishes relatively well between two different editions of this journal. The comparatively high JIF of ACP in the JCR subject category 'Meteorology \& Atmospheric Sciences' is thus calculated correctly and is not an effect of the two-stage publication process. Further studies should clarify whether the results of this study also hold for other interactive open access journals (of the Copernicus Society), such as Biogeosciences or Climate of the Past. Unlike ACP, these journals are predominantly launched only a few years ago.

Acknowledgements The research project is investigating quality assurance of interactive open access journals and is supported by a grant from the Max Planck Society (Munich, Germany). We thank Marie E. McVeigh, Senior Manager JCR and Bibliographic Policy at Thomson Reuters, for her comments on a previous version of our paper.

\section{References}

Amin, M., \& Mabe, M. A. (2003). Impact factors: Use and abuse. Medicina-Buenos Aires, 63(4), 347-354. Archambault, É., \& Larivière, V. (2009). History of the journal impact factor: Contingencies and consequences. Scientometrics, 79(3), 635-649.

Bornmann, L., Leydesdorff, L., \& Marx, W. (2007). Citation environment of Angewandte Chemie. CHIMIA, 61(3), 104-109.

Braun, T., \& Glänzel, W. (1995). The sweet and sour of journal citation rates. On a source of error in computing impact factors. The Chemical Intelligencer, 31-32. 
Garfield, E. (1976). Significant journals of science. Nature, 264(5587), 609-615.

Glänzel, W., \& Moed, H. F. (2002). Journal impact measures in bibliometric research. Scientometrics, 53(2), $171-193$.

Koop, T., \& Pöschl, U. (2006). Systems: an open, two-stage peer-review journal. The editors of Atmospheric Chemistry and Physics explain their journal's approach. Retrieved 26 June 2006, from http://www. nature.com/nature/peerreview/debate/nature04988.html.

Kumar, V., Upadhyay, S., \& Medhi, B. (2009). Impact of the impact factor in biomedical research: Its use and misuse. Singapore Medical Journal, 50(8), 752-755.

Kurtz, M., \& Brody, T. (2006). The impact loss to authors and readers. In N. Jacobs (Ed.), Open access: Key strategic, technical and economic aspects (pp. 45-54). Oxford: Chandos Publication.

Magri, M.-H., \& Solari, A. (1996). The SCI Journal Citation Reports: A potential tool for studying journals? Scientometrics, 35(1), 93-117.

Marx, W. (2001). Angewandte Chemie in light of the "Science Citation Index". Angewandte Chemie International Edition, 40(1), 139-143.

McVeigh, M. E. (2010). Journal Impact Factor (JIF) of Atmospheric Chemistry and Physics (ACP).

Moed, H. F., van Leeuwen, T. N., \& Reedijk, J. (1996). A critical analysis of the journal impact factors of Angewandte Chemie and the Journal of the American Chemical Society-inaccuracies in published impact factors based on overall citations only. Scientometrics, 37(1), 105-116.

Pendlebury, D. A. (2009). The use and misuse of journal metrics and other citation indicators. Archivum Immunologiae et Therapiae Experimentalis, 57(1), 1-11. doi:10.1007/s00005-009-0008-y.

Pöschl, U. (2004). Interactive journal concept for improved scientific publishing and quality assurance. Learned Publishing, 17(2), 105-113.

Retzer, V., \& Jurasinski, G. (2009). Towards objectivity in research evaluation using bibliometric indicators: A protocol for incorporating complexity. Basic and Applied Ecology, 10(5), 393-400. doi:10.1016/ j.baae.2008.09.001.

Todd, P. A. (2009). Ambiguity, bias, and compromise: An abc of bibliometric-based performance indicators Introduction. Environment and Planning A, 41(4), 765-771. doi:10.1068/a424. 